九州大学学術情報リポジトリ

Kyushu University Institutional Repository

\title{
Preliminary Column Experiment on Dynamics of Water and Ion Transport in Soil Affected by Root Absorption
}

Urayama, Kazuki

Graduate School of Bioresource and Bioenvironmental Sciences, Kyushu University

Sakata, Yoshinobu

Ex-student

Sonoda, Yasutaka

Ex-student

Ebihara, Kenji

Graduate School of Bioresource and Bioenvironmental Sciences, Kyushu University

他

https://doi.org/10.5109/12871

出版情報：九州大学大学院農学研究院紀要. 53 (2)，pp.543-547，2008-10-28. Faculty of Agriculture, Kyushu University

バージョン :

権利関係 : 


\title{
Preliminary Column Experiment on Dynamics of Water and Ion Transport in Soil Affected by Root Absorption
}

\section{Kazuki URAYAMA ${ }^{1}$, Yoshinobu SAKATA ${ }^{2}$, Yasutaka SONODA ${ }^{2}$, Kenji EBIHARA ${ }^{1}$, Yuki SAGO ${ }^{1}$, Hisashi YOSHIKOSHI, Takuya ARAKI ${ }^{3}$, Daisuke YASUTAKE ${ }^{4}$, Hiroyuki $\mathrm{CHO}^{5}$, Tetsuo KOBAYASHI and Masaharu KITANO*}

\author{
Laboratory of Applied Meteorology, Division of Regional Environment Science, Department of \\ Bioproduction Environmental Sciences, Faculty of Agriculture, \\ Kyushu University, Fukuoka 812-8581, Japan \\ (Received June 27, 2008 and accepted July 16, 2008)
}

\begin{abstract}
Water deficit and salt accumulation in soil are serious problems in crop fields in semi-arid regions, and these problems are likely to depend on active transpiration and selective ion absorption by crop roots. In this study, a large sized soil column system was newly developed, and a preliminary experiment with the system was conducted to examine the system performance for analyses of dynamics of water and ion transport and salt accumulation in soil with special reference to effects of the active and selective absorption of roots of different crops (i.e., corn plants, sunflower plants and no plants). The column system was equipped with on-line systems for the control of groundwater level and the TDR measurement, which enabled time course evaluations of upward flux of the groundwater, volumetric water content of soils at the different depths and electrical conductivity of the extract from the saturated soil. Furthermore, distribution and accumulation of ions in soil layers, plant organs and xylem sap were analyzed using an ion chromatograph. In this column experiment, diurnal and long term daily changes in water movement and ions accumulation in soil affected by characteristics of root absorption were evaluated. This can suggest that this column system is applicable for quantitative analyses of effects of root absorption of different crops on water deficit and salinization in soils, aiming at proposing a scientific method of the crop rotation for the environmentally conscious agriculture in semi-arid regions.
\end{abstract}

Keywords: soil salinization, root absorption, column experiment, TDR

\section{INTRODUCTION}

Water deficit and salt accumulation in soil are serious problems in crop fields in semi-arid regions, which are affected by dynamics of water and ion transport in the soil-plant-atmosphere continuum. The water and ion transport in crop fields is driven through physical and physiological processes, but the transport phenomena in root zone soil have been studied mainly through physical processes, because of difficulties in quantitative analyses of root physiological functions (i.e. water and ion absorption) in crop fields (Hillel, 1998). In a cornfield in the semi-arid region of the upper Yellow River basin, the crop transpiration accounted for $83.4 \%$ of the water loss from the cornfield during the crop development stage, and $\mathrm{Na}^{+}$was scarcely absorbed by roots and was remained in the root zone soil and resultantly in the groundwater with the significantly higher concentrations (Kitano et al., 2006). This result can suggest that crop

Graduate School of Bioresource and Bioenvironmental Sciences, Kyushu University, Fukuoka 812-8581, Japan

Ex-student

Laboratory of Plant Production Physiology, Division of Soil Science and Plant Production, Department of Plant Resources, Faculty of Agriculture, Kyushu University, Fukuoka 812-8581, Japan

${ }^{4}$ Faculty of Agriculture, Kochi University, Nankoku 783-8502, Japan

${ }^{5}$ Department of Agricultural Sciences, Saga University, Saga 840-8502, Japan

* Corresponding author (E-mail: kitano@bpes.kyushu-u.ac.jp) transpiration but not soil evaporation induces the most significant driving force for mass flow transporting the groundwater to the root zone and dynamics of ion balance largely depends on the selective ion absorption by roots. Water and ion absorption in roots is characterized by transport mechanisms such as pumps, channels and transporters in root cell membranes, which play important roles especially in the radial flow across root endodermis (Taiz and Zeiger, 2002).

In crop fields under soil salinization in semi-arid regions, a scientific method for the crop rotation based on characteristics of root absorption of the respective crops is likely to contribute to the environmentally conscious and sustainable agriculture in semi-arid regions. In this study, a preliminary experiment with large sized columns was conducted for analyses of water and salt transport in soil affected by the active and selective absorption of crop roots.

\section{MATERIALS AND METHODS}

\section{Column system}

Figure 1 shows a schematic diagram of column experiment for analyses of water and ion transport in soil, where (A) is the overview of the column system, and (B) is the control unit of groundwater level. The plastic column $1.0 \mathrm{~m}$ in height and $0.5 \mathrm{~m}$ in internal diameter is filled with soil, where water permeable spacer and sheet are set at the bottom (Fig. 1(A)). Ground water level in the column is sensed by the water level 

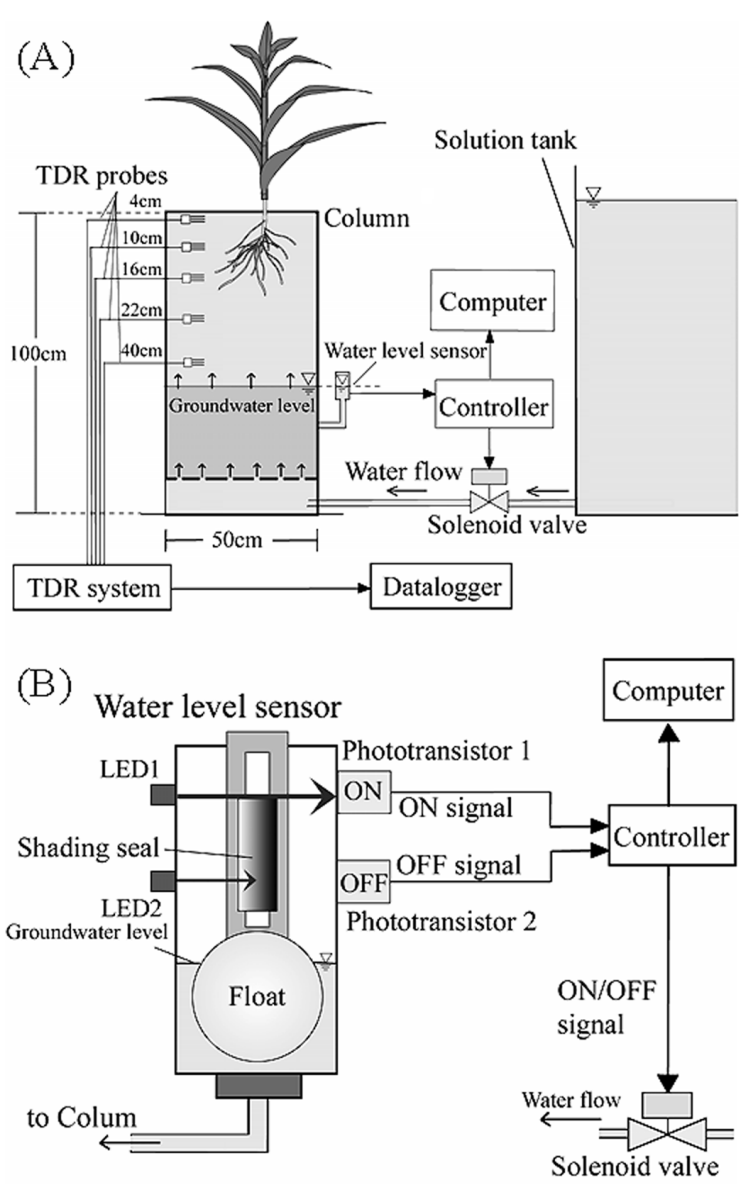

Fig. 1. Schematic diagram of column experiment for analyses of water and ion transport in soil: (A) is the overview of the column system, and (B) is the control unit of groundwater level. Groundwater level in the column can be controlled by the on-off action of water supply from the solution tank through the solenoid valve, and the on-off action of water supply is manipulated by the control unit which consists of a water level sensor, an on-off signal generator (two pairs of LED and phototransistor) and a controller. The on-off signal from the controller is monitored on-line by a computer. Volumetric water content of soils at different five depths and electrical conductivity $\left(E C_{\mathrm{SAT}}\right)$ of the extract from the soils saturated with water can be evaluated by the TDR system.

sensor newly developed (Fig. 1(B)) and can be controlled at a desired depth by the on-off action of the water supply solenoid valve between the column bottom and the nutrient solution tank with a capacity of $200 \mathrm{~L}$. The desired depth of the groundwater level can be changed by adjusting the position of the water level sensor. The on-off action of water supply is manipulated by the control unit which consists of the water level sensor, an onoff signal generator (two pairs of LED and phototransistor) and a controller (Fig. 1(B)). When the groundwater level in the column becomes lower than the desired level, the shading seal on the float in the water level sensor passes the beam from LED1 to the phototransistor1, and the signal for opening the solenoid valve is transmitted to the controller. Furthermore, when the groundwater level is recovered to the desired level, the beam from LED2 to the phototransistor2 generates the signal for closing the solenoid valve. These on-off signals through the controller are monitored on-line by a computer, and the quantity of water supplied to the column bottom through the on-off action of the solenoid valve can be evaluated on the basis of duration of the opened-valve monitored by the computer, which can be considered to be equal to the upward flux of groundwater in the column. In this system, eight sets of the column and the control unit of the groundwater can be supported by the nutrient solution tank.

\section{TDR measurements}

For measuring time course changes in water and salt movement in the soil column, the time domain reflectometry (TDR) method was applied. TDR probes (CS645, CAMPBELL) with the wave-guide composed of three rods of $7.5 \mathrm{~cm}$ long, $0.159 \mathrm{~cm}$ diameter and $0.75 \mathrm{~cm}$ spacing were set in the soil column at five different depths of 4, 10, 16, 22 and $40 \mathrm{~cm}$, and the data processing was supported by a TDR system (TDR100, CAMPBELL) and a data logger (CR23X, CAMPBELL) with intervals of $30 \mathrm{~min}$. On the basis of data from the TDR system, volumetric water content of soils at the different depths and electrical conductivity $\left(E C_{\mathrm{SAT}}\right)$ of the extract from the saturated soil were evaluated at intervals of $30 \mathrm{~min}$ with the manners newly proposed by Wang et al. (2005) and Kobayashi et al. (2006). $E C_{\mathrm{SAT}}$ is defined as the electrical conductivity of the extract from the soil which is saturated with distilled water and can be used as an easily measurable and practical index representing the total content of soluble ions in the soil without effect of change in soil water content (Kobayashi et al., 2006).

\section{Experimental conditions and material plants}

Three columns were placed in a greenhouse and filled with an arkose sand (clay : silt : sand=6.2 : 3.1 : 90.7 ) at a dry density of $1.53 \mathrm{gcm}^{-3}$ and a porosity of 0.44 . The nutrient solution in the tank (i.e. groundwater) was adjusted at an electrical conductivity of $5.0 \mathrm{dSm}^{-1}$ with $\mathrm{NO}_{3}^{-} 3.41, \mathrm{PO}_{4}^{3-} 0.30, \mathrm{~K}^{+} 1.86, \mathrm{Na}^{+} 23.11$, $\mathrm{Mg}^{2+} 8.36, \mathrm{Ca}^{2+} 5.04, \mathrm{Cl}^{-} 29.95$ and $\mathrm{SO}_{4}^{2-} 11.10 \mathrm{mmol} \mathrm{L}{ }^{-1}$, which was specially enriched with $\mathrm{Na}^{+}, \mathrm{Ca}^{2+}$ and $\mathrm{Mg}^{2+}$ to the respective high concentrations found in the groundwater of a salinized field in the upper Yellow River basin (Yasutake et al., 2008). Corn (Zea mays L.) and sunflower (Helianthus annuus L.) plants were used for the column experiment. Three weeks after sowing, the respective three plants of corn and sunflower were transplanted to each column, and the other column was not cropped (i.e. bare soil). Before the start of the experiment, all the soil in each column was saturated with the nutrient solution by setting the groundwater level at the soil surface. Thereafter, the groundwater level was set at a depth of $50 \mathrm{~cm}$ by adjusting the water level sensor, and the experiment was started after the gravitational water in soil above the groundwater level was drained. The experiment was started on 26 Nov., 2007 and ended on 4 Jan., 2008. The desired depth $(d)$ of the groundwater level in the columns were set at $d=50 \mathrm{~cm}$ during the experiment. Short wave radiant flux 
density of solar radiation and air temperature and humidity near the plants were also measured on-line.

\section{Analysis of samples}

At the start and the end of the experiment, soils around TDR probes at the respective depths and material plants were sampled, and physical properties of the soils and growth of the plants were analyzed with the routine manners. The concentrations of the respective ions of $\mathrm{NO}_{3}^{-}, \mathrm{PO}_{4}^{3-}, \mathrm{K}^{+}, \mathrm{Na}^{+}, \mathrm{Mg}^{2+}, \mathrm{Ca}^{2+}, \mathrm{Cl}^{-}$and $\mathrm{SO}_{4}^{2-}$ in the respective samples of soils, plants and nutrient solution (i.e. groundwater) were analyzed using the ion chromatograph system (ICS-90, DIONEX) following the standard procedures. Accumulation of each ion in the soil layers and the material plants during the experiment was evaluated on the basis of increase in concentration of each ion in the soils and the plants from the start of the experiment.

Roots can generate positive hydrostatic pressure (root pressure) in the nighttime by absorbing ions actively and transporting them into the xylem (Taiz and Zeiger, 2002). If the stem of a plant is cut off just above the soil, the stump often exudes sap from the cut xylem for many hours. Therefore, the ion composition of this stem stump exudates can be considered to reflect clearly the active and selective ion absorption by roots without the significant effect of dilution due to the transpiration stream. In this experiment, the xylem saps exuded from the stem stumps of respective three corn and sunflower plants were collected during the nighttime just after the end of the experiment (Kitano et al., 1999; Kitano et al., 2006). The ions concentrations of the exudates were also analyzed by the ion chromatograph system.

\section{RESULTS AND DISCUSSION}

Figure 2 shows diurnal changes in solar radiation, upward flux of groundwater, volumetric water content of soil at a depth of $22 \mathrm{~cm}$ and electrical conductivity $\left(E C_{\mathrm{SAT}}\right)$ of the extract of the saturated soil in the column cropped with corn plants from Dec.15 to Dec.18. Solar radiation induced evapotranspiration and resultantly dynamics of upward water transport in the soil. Water content of the soil layer at a depth of $22 \mathrm{~cm}$, where is just under the highest root density of corn plants, showed the delayed response to solar radiation and decreased in the nighttime. The upward flux of groundwater was induced from the late afternoon to the next morning, and this upward flux of groundwater replenished soil water content at a depth of $22 \mathrm{~cm}$. $E C_{\mathrm{SAT}}$ also fluctuated, but its fluctuation appeared to be independent of change in water content of the soil as defined by Kobayashi et al. (2006). Figure 3 shows long term daily changes in volumetric water content of soils at the respective depths of $4,10,16$ and $22 \mathrm{~cm}$ and increment $\left(\Delta E C_{\mathrm{SAT}}\right)$ of electrical conductivity of the extract of the saturated soils in the column cropped with corn plants during the experiment. Soil water contents at the respective depths were almost kept constant at different

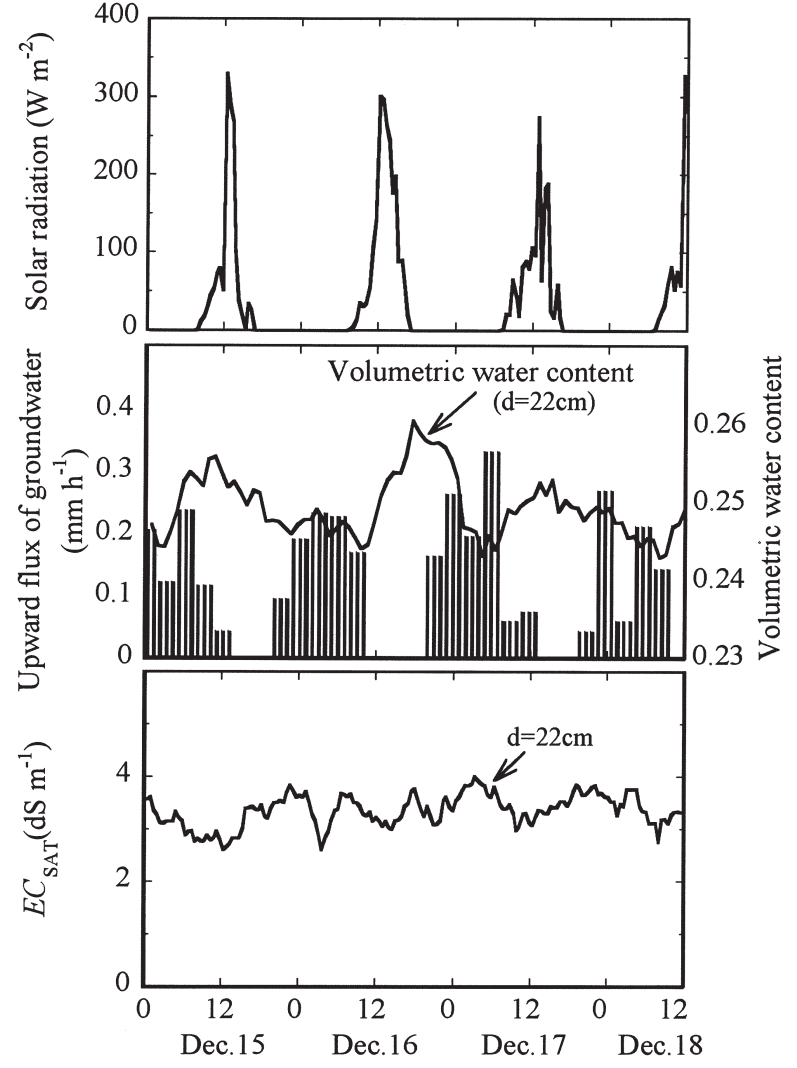

Time of day (Dec. 15 - 18)

Fig. 2. Diurnal changes in solar radiation, upward flux of groundwater, volumetric water content of soil at a depth of $22 \mathrm{~cm}$ and electrical conductivity $\left(E C_{\mathrm{SAT}}\right)$ of the extract of the soil saturated with water in the column cropped with corn plants from Dec.15 to Dec.18.
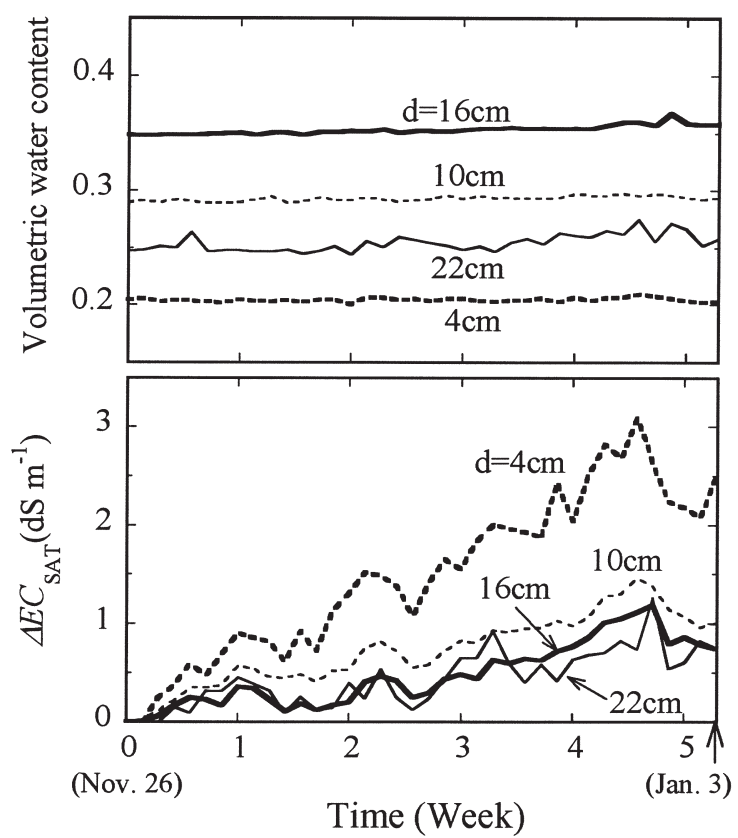

Fig. 3. Daily changes in volumetric water content of soils at the respective depths of $4,10,16$ and $22 \mathrm{~cm}$ and increment $\left(\triangle E C_{\mathrm{SAT}}\right)$ of electrical conductivity of the extract of the soils saturated with water in the column cropped with corn plants from Nov. 26, 2007 to Jan. 3, 2008. 
values. The lowest water content was found in the soil layer at a depth of $4 \mathrm{~cm}$ near the soil surface, and the second lowest water content was found in the soil layer at a depth of $22 \mathrm{~cm}$ just under the highest root density. The highest water content found in the soil layer at a depth of $16 \mathrm{~cm}$ could be brought by the TDR measurement affected by the highest density of roots of which water content is around 0.9. $\Delta E C_{\mathrm{SAT}}$ was significantly increased in the respective soil layers, and the largest increase was found in the layer near the soil surface with the lowest root density. This indicates that the soluble ions which were not absorbed by roots were accumulated to the layer near the soil surface evaporating water.

Figure 4 shows long term changes in daily integrated solar radiation and upward flux of groundwater in the respective columns cropped with corn plants, sunflower plants and no plants (i.e. bare soil) from Dec.10 to Dec.21, 2007. The upward flux of groundwater was remarkably high in the sunflower column, and it seemed to increase with increase in solar radiation and plant growth. Figure 5 shows concentration of $\mathrm{K}^{+}, \mathrm{Na}^{+}, \mathrm{Ca}^{2+}$ and $\mathrm{Mg}^{2+}$ in the groundwater and xylem saps in corn and sunflower plants. $\mathrm{K}^{+}$ion, which is one of major essential nutrients, was actively concentrated in xylem sap of plants even under the low concentration in the groundwater. On the other hand, $\mathrm{Na}^{+}$ion, which is not essential for plant growth, was scarcely concentrated in xylem sap of plants even under the extremely high concentration in the groundwater. $\mathrm{Ca}^{2+}$ and $\mathrm{Mg}^{2+}$ ions, which are also major essential nutrients, were concentrated in xylem sap in different manners between corn and sunflower plants. The concentrations of $\mathrm{Ca}^{2+}$ and $\mathrm{Mg}^{2+}$ ions in xylem sap of the sunflower were remarkably higher than those in the groundwater and the corn plant xylem sap. This indicates that sunflower roots absorb $\mathrm{Ca}^{2+}$ and $\mathrm{Mg}^{2+}$ ions through the active functional absorption mechanism in addition to the mass flow driven by transpiration, while $\mathrm{Ca}^{2+}$ and $\mathrm{Mg}^{2+}$ absorption by corn roots depends on the mass flow. Figure 6 shows accumulation of $\mathrm{K}^{+}, \mathrm{Na}^{+}$, $\mathrm{Ca}^{2+}$ and $\mathrm{Mg}^{2+}$ in corn and sunflower plants. The higher accumulations of the respective ions were found in organs of sunflower plants, which showed remarkably high absorption of water (Fig. 4) and active absorption of $\mathrm{Ca}^{2+}$ and $\mathrm{Mg}^{2+}$ (Fig. 5). Figure 7 shows accumulation of $\mathrm{K}^{+}, \mathrm{Na}^{+}, \mathrm{Ca}^{2+}$ and $\mathrm{Mg}^{2+}$ in soil layers at different depths in the respective columns cropped with corn plants, sunflower plants and no plants. $\mathrm{K}^{+}$ion actively absorbed by roots was scarcely accumulated in soil. On the other hand, $\mathrm{Na}^{+}, \mathrm{Ca}^{2+}$ and $\mathrm{Mg}^{2+}$ ions derived from the salinized groundwater were highly accumulated in the respective soil layers, and this ion accumulation in soil was highest in the sunflower column and lowest in the no plants column. These results suggest that salt accumulation in root zone soil largely depends on mass flow with the upward flux of groundwater driven by root water absorption. However, there was the inexplicable result that the accumulation of $\mathrm{Ca}^{2+}$ ion in soil was excessively higher than that of $\mathrm{Na}^{+}$ion which was highly concentrated in the groundwater and was scarcely absorbed by roots. The liquation of $\mathrm{Ca}^{2+}$ ion from the material soil of arkose sand to the soil water can possibly be a reason of the excessive accumulation of $\mathrm{Ca}^{2+}$ ion in soil layers, but the further experiments are necessary.

From these results, it can be suggested that this column experiment system equipped with the control system of groundwater level and the on-line TDR system is

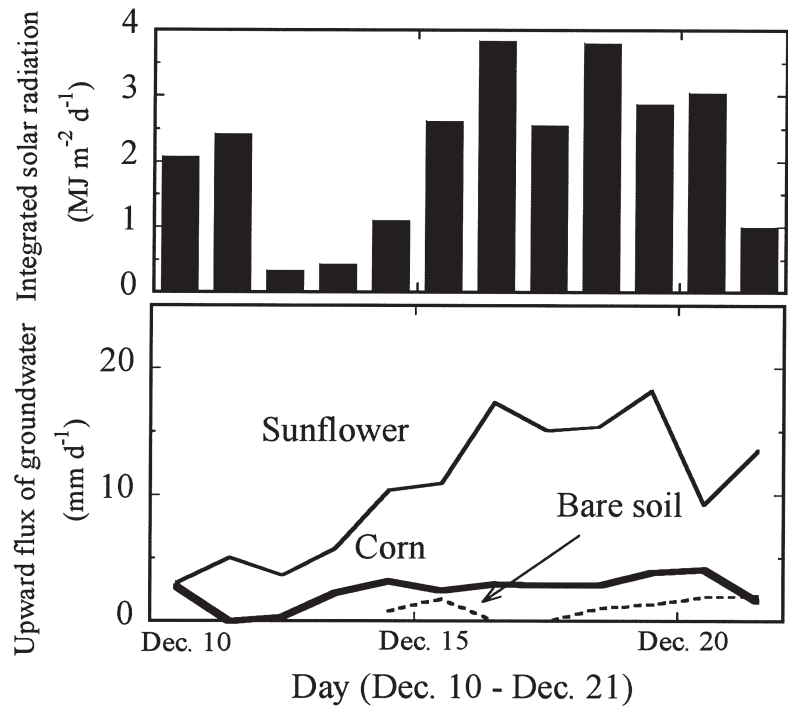

Fig. 4. Daily changes in integrated solar radiation and upward flux of groundwater in the respective columns cropped with corn plants, sunflower plants and no plants (i.e. bare soil) from Dec.10 to Dec.21, 2007.

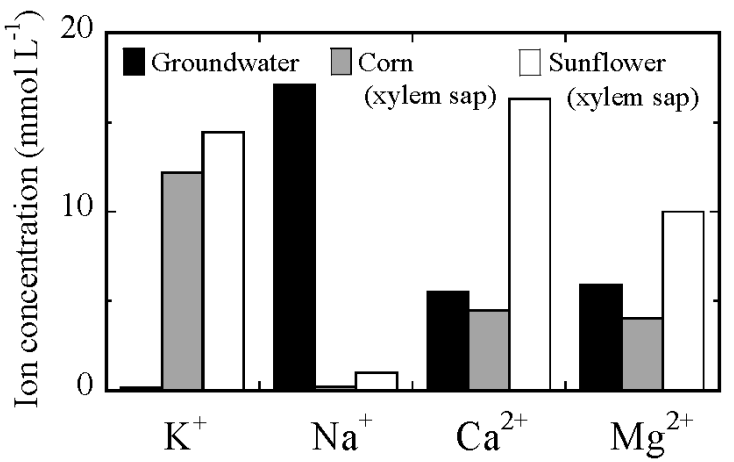

Fig. 5. Concentration of $\mathrm{K}^{+}, \mathrm{Na}^{+}, \mathrm{Ca}^{2+}$ and $\mathrm{Mg}^{2+}$ in groundwater and xylem saps in corn and sunflower plants.

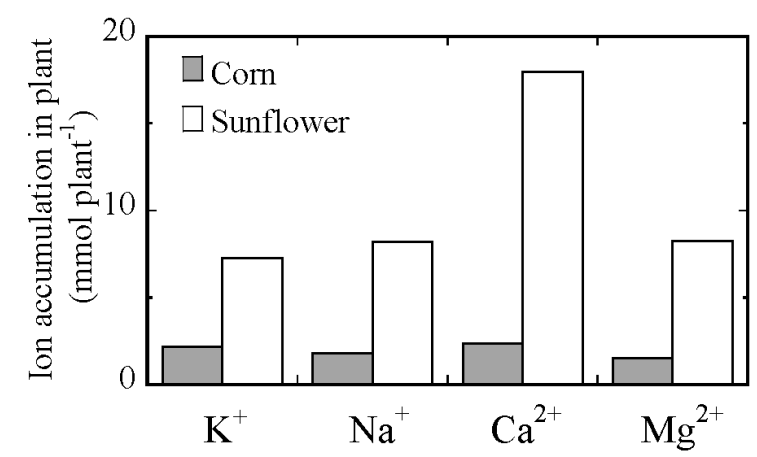

Fig. 6. Accumulation of $\mathrm{K}^{+}, \mathrm{Na}^{+}, \mathrm{Ca}^{2+}$ and $\mathrm{Mg}^{2+}$ in corn and sunflower plants. 


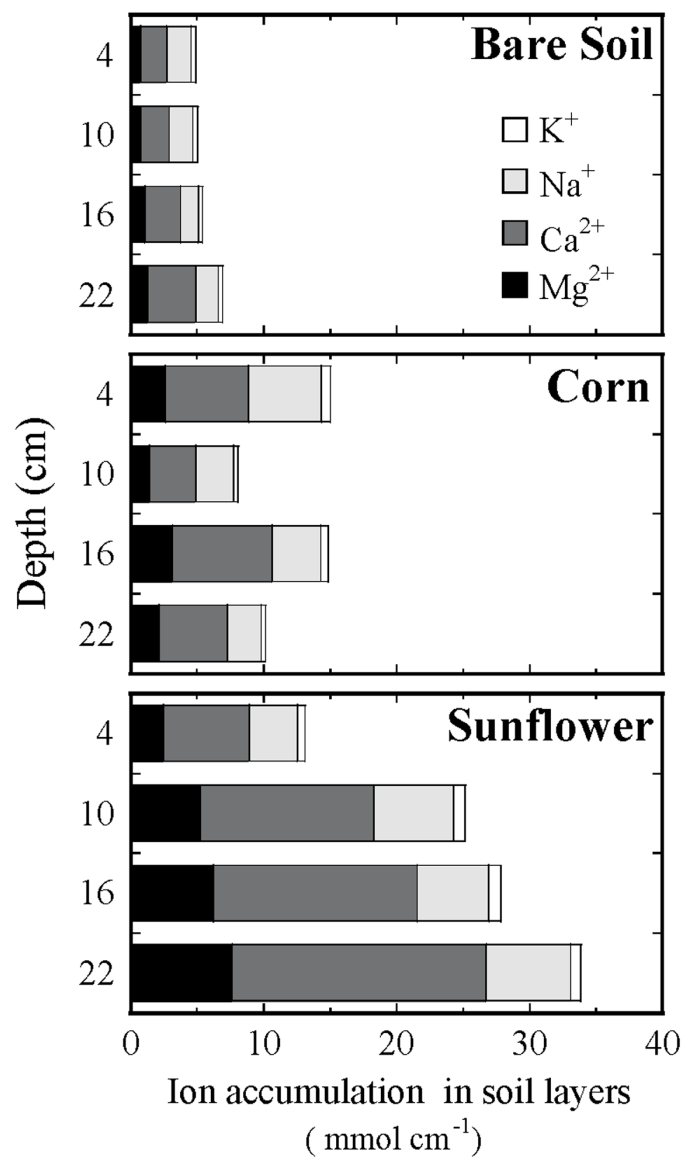

Fig. 7. Accumulation of $\mathrm{K}^{+}, \mathrm{Na}^{+}, \mathrm{Ca}^{2+}$ and $\mathrm{Mg}^{2+}$ in soil layers at different depths in the respective columns cropped with corn plants, sunflower plants and no plants (i.e. bare soil).

applicable for quantitative analyses of effects of root absorption of different crops on dynamics of water and ion transport and salt accumulation in soil, aiming at proposing a scientific method of the crop rotation for the environmentally conscious agriculture in semi-arid regions.

\section{ACKNOWLEDGEMENTS}

This research was supported by Grant-in-Aid for Scientific Research (No.19405039 and No.20380141) from the Japan Society for the Promotion of Science. The authors would like to thank Mr. M. Hamakoga (Biotron Institute, Kyushu University) for his cooperation.

\section{REFERENCES}

HILLEL, D. 1998 Environmental soil physics. Academic Press, San Diego, pp. 771

Kitano, M., T. Araki, S. Yoshida and T. Eguchi 1999 Dependence of calcium uptake on water absorption and respiration in roots of tomato plants (Lycopersicon esculentum Mill), Biotronics, 28: $121-130$

Kitano, M., D. Yasutake, T. Kobayashi, K. Hidaka, T. Wajima, W. Wang and W. He 2006 Dynamics of water and ion transport driven by corn canopy in the Yellow River basin. Biologia, 61(Suppl.19): S275-S279

Kobayashi, T., W. Wang, Y. Ikawa, H. Cho and W. He 2006 An easily measurable and practical index of soil salinity. J. Jap. Soc. Hydrol. \& Water Resour., 19: 183-188

Taiz, L. and E. Zeiger 2002 Plant Physiology. 3rd edition. Sinauer Associates, Sunderland, pp. 691

Wang, W., E.Watanabe, T. Kobayashi, H. Cho, W. He and N. Mohri 2005 A Method for measuring soil solution electrical conductivity in the field using TDR. J. Japan Soc. Hydrol. \& Water Resour., 18: 55-63

Yasutake, D., T. Araki, M. Kitano, W. Wang, K. Urayama, H. Cho and T. Kobayashi 2008 Experiments on the control of salinity and sodicity in surface-irrigated fields in the upper Yellow River valley (III). The State of Salinization and Alkalization in and around the Pingpu Experimental Field. J. Fac. Agr., Kyushu Univ., 53: 265-270 